\title{
Numerical investigation of the influence of earthquake forces and foundation settlement on the performance of Post-Byzantine churches
}

\author{
G. C. Manos, L. Kotoulas \& V. Matsou \\ Laboratory of Strength of Materials and Structures, \\ Department of Civil Engineering, Aristotle University of Thessaloniki, \\ Greece
}

\begin{abstract}
The earthquake performance of stone masonry Post-Byzantine churches subjected to seismic forces is examined. First, a three-nave Basilica is studied with a system of stone-masonry vaults and domes as a superstructure together with a wooden roof. Next, a cruciform type 18th century church is studied which also utilizes a system of cylindrical vaults and spherical domes that form the superstructure together with the wooden roof. In addition, a three-nave 18th century Basilica is examined where the wooden roof is supported directly on the peripheral masonry walls and the internal colonnades. All these churches developed structural damage to the masonry that is believed to arise from the amplitude of the gravitational and seismic actions combined with the deformability of the foundation, which is examined here. It is shown that the foundation deformability explains, partly, the appearance of structural damage. The numerically predicted regions that reach limit state conditions correlate well with actual damage patterns. Moreover, the vaults and domes of the superstructure appear to be vulnerable also.

Keywords: Byzantine churches, stone masonry, dynamic response, earthquake performance, foundation settlement.
\end{abstract}

\section{Introduction}

During the last thirty years various parts of Greece have been subjected to a number of damaging earthquakes ranging from $\mathrm{Ms}=5.2$ to $\mathrm{Ms}=7.2$ on the Richter scale. One of the most demanding tasks for counteracting the consequences of all 
these seismic events was the effort to ensure the structural integrity of old churches that were built in periods ranging from $400 \mathrm{AD}$ up to today; in many cases they sustained considerable damage [3]. The earthquake behaviour of churches belonging to the so-called Post-Byzantine period (16th to 19th century $\mathrm{AD})$ has been studied numerically in some detail [1, 2]. In all these cases the foundation was considered to be non-deformable. However, this is a gross approximation as in most cases these churches are founded on deformable soil. In some instances, the deformability of the soil caused considerable damage as is the case of the church of The Assumption of Virgin Mary at Dilofo-VoioKozani, as will be presented in section 2. In some other cases the main cause of recent damage is the earthquake activity that is accentuated by the deformability of the soil. This will be presented in the sections 3 and 4 , where the damage of the church of Agia Triada at Vithos-Kozani and of Profitis Elias at SiatistaKozani is also included. It must be noted that these churches were built in a number of phases on old existing sacred sites by extending old remains, due to prohibitions by the Turkish occupation authorities imposed on the Christian population forbidding the construction of new churches but only allowing the maintenance of existing ones, after special permit [7].

\section{The Assumption of Virgin Mary}

The outlay of this church is shown in figure 1 by a cross-section in the longitudinal direction. Its basic dimensions are 21.5m long (together with the apse of the East wall) $11 \mathrm{~m}$ wide and a maximum height to the top of the wooden roof $10 \mathrm{~m}$. With the dashed line the hard-soil is indicated.

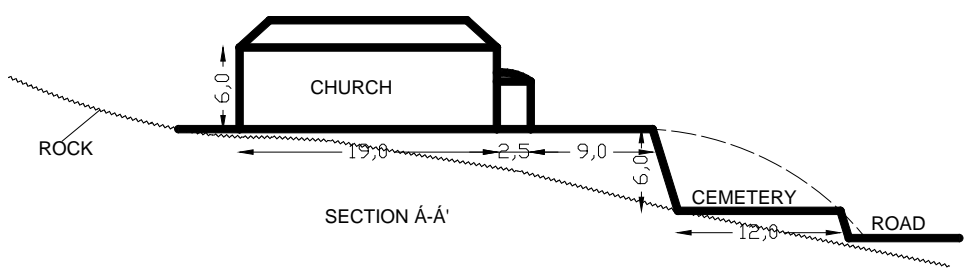

Figure 1: The layout of the church of Virgin Mary.

As can be seen, the West part of this church is founded on hard soil (weathered flysch layers) whereas the East part is founded on relatively soft soil that was deposited on top of the layers to compensate for the natural slope at this location. Apart from the relatively soft soil deposits at the East part of this church the malfunction of the drainage system at this point initiated considerable settlement of these soft soil deposits. The unequal settlement of the foundation of the stone masonry walls as well as of the internal columns that supported the vaulting system, which covered this church, caused consider-able damage. The extensive damage that developed at the South-East corner is depicted. A very wide crack initiates at the top of the East peripheral wall near the apse and propagates towards the bottom of this wall being inclined to the South-East 
corner (figure 2). Furthermore, a similarly wide crack propagates through the North peripheral wall from top to bottom. It must be noted that the thickness of these masonry walls varies from $750 \mathrm{~mm}$ to $800 \mathrm{~mm}$. From this extensive peripheral wall damage, the vaulting system that is supported by these peripheral walls also suffered extensive cracking that eventually caused the partial collapse of a part of the central dome, as shown in figure 3 .

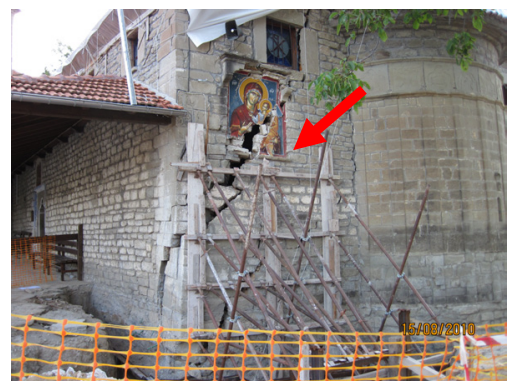

Figure 2: $\quad$ Partial collapse of the central dome.

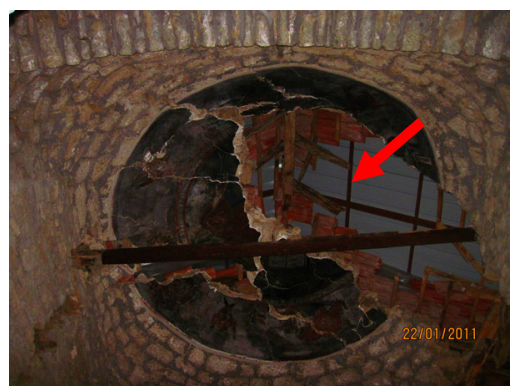

Figure 3: Damage to the SouthEast corner.

\subsection{Numerical simulations}

Initially, the numerical simulation assumed that the foundation was nondeformable. Based on this assumption the 3-D numerical representation of the church, including the peripheral walls, the vaulting system of the superstructure and the wooden roof were subjected to load combinations of either $0.9 \mathrm{G} \pm 1.4 \mathrm{Ex}$ or $0.9 \mathrm{G} \pm 1.4 \mathrm{Ey}$, where $\mathrm{G}$ is the gravitational loads and $\mathrm{Ex}$, Ey the earthquake forces ([4]) along the $\mathrm{x}-\mathrm{x}$ axis (longitudinal East-West direction) or the $\mathrm{y}-\mathrm{y}$ axis (transverse North-South direction, respectively.

All the supports were assumed to prohibit the translations along all three axes but not to restrain the rotations. It was found from previous studies that full fixity of the masonry walls at the foundation level leads to the development of considerable bending moments that correspond to tensile stresses, which cannot be sustained by the weak stone masonry used to construct these churches. For the load combination 0.9G+1.4(+Ex) the maximum deformations at the top of the central dome were found equal to $\mathrm{Ux}=6.81 \mathrm{~mm} \mathrm{Uz}=-1.51 \mathrm{~mm}$. For this load combination the maxi-mum tensile stresses parallel to the bed joint $\sigma 11$ were found equal to $0.51 \mathrm{MPa}$, at the bottom face of the masonry walls. High tensile stresses parallel to the bed joint develop both at the top of the North wall as well at the South-East corner of the East wall (figure 3(a)).

\subsubsection{State of stress arising from the foundation settlement}

Next, layers of deformable soil were introduced beneath the foundation of all the peripheral walls and internal colonnades. The stiffness of these soil layers was varied in order to simulate the relatively hard soil at the West part of the church 
and the relatively soft soil at the North-East part of the church (see figure 1). For quantifying the stiffness of these soil layers use was made of the data from three boreholes drilled at the vicinity of the church relevant to the constitution of the soil deposits at a depth up to $10 \mathrm{~m}$. For the load combination 0.9G+1.4(+Ex), the maximum deformations at the top of the central dome were found equal to $\mathrm{Ux}=$ $21.33 \mathrm{~mm}, \mathrm{Uz}=-14.80 \mathrm{~mm}$, a considerable increase in the deformation at the top of the church from the previous case where the soil was considered nondeformable. Figure 4(b) depicts the distribution of stresses $\boldsymbol{\sigma}_{\mathbf{1 1}}$ parallel to the bed joint; the maximum tensile values were found equal to $0.64 \mathrm{MPa}$, at the bottom face of the masonry walls. As can also be seen in this figure, high tensile stresses parallel to the bed joint develop both at the top of the North wall and at the South-East corner of the East wall. The increase in the tensile stresses for the deformable soil is of the order of $30 \%$ to $50 \%$ when compared to the corresponding maximum tensile stresses when that the soil was considered nondeformable. As could be seen from the preceding numerical study, the uneven deformability of the soil under the foundation of such structural formations, as Post-Byzantine Basilica churches, can introduce an increase in the critical tensile stresses. The regions of such tensile stress concentration correlate reasonably well with the areas of observed damage.

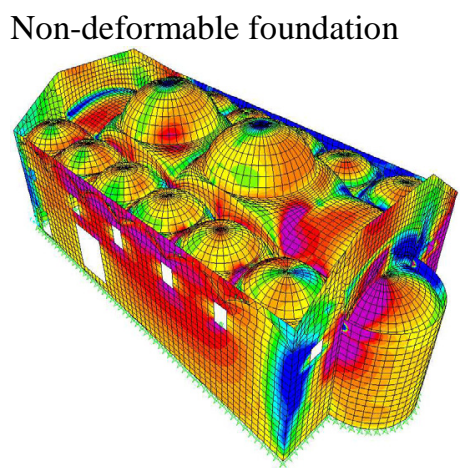

(a)

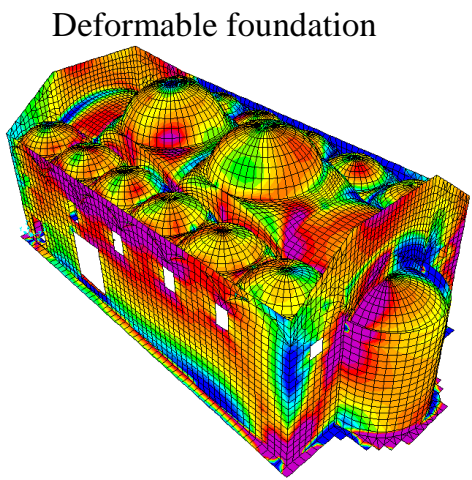

(b)

Figure 4: Out-of-plane behaviour, Load Combination 0.9G+1.4(+Ex). (a) $\sigma_{11}$ bottom face, $\max \sigma=0.51 \mathrm{MPa}$; (b) $\sigma_{11}$ bottom face max $\sigma=$ $0.64 \mathrm{MPa}$.

\section{The Agia Triada (Holy Trinity) at Vithos-Voio-Kozani}

This is a Post-Byzantine church of the cruciform type with three domes (figures 5). The central dome rises at the highest elevation to $15.75 \mathrm{~m}$ from ground level; the length of the church in the longitudinal East-West direction is $17.60 \mathrm{~m}$ and its width in the North-South direction is $9.85 \mathrm{~m}$. The construction of this stone-masonry church was completed in $1797 \mathrm{AD}$ using local natural stone. 
The vaulting system that supports the three domes is depicted in figures 5(a) and 5(b), as can be seen from the top by removing the wooden roof. The numerical simulation considered two distinct models. The first model assumed non-deformable foundation where the translations along the three axes (x, y, z) were restrained to zero. The second model tries to account for the deformability of the foundation by using as supports linear springs with stiffness properties that were estimated taking into consideration the quality of the underlying media as well as the thickness of the foundation and the discretization employed.

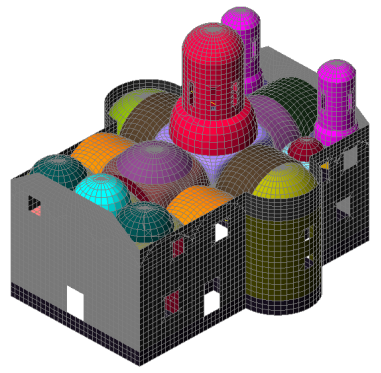

(a)

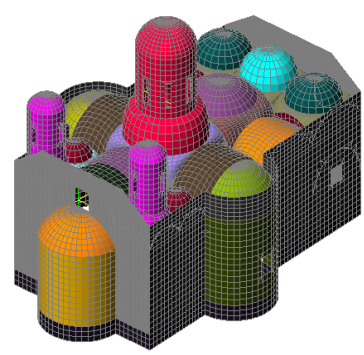

(b)

Figure 5: (a) View from the South-West; (b) View from the North-East.

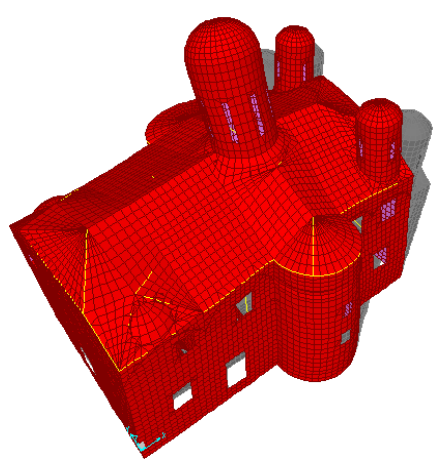

(a) Non-deformable foundation

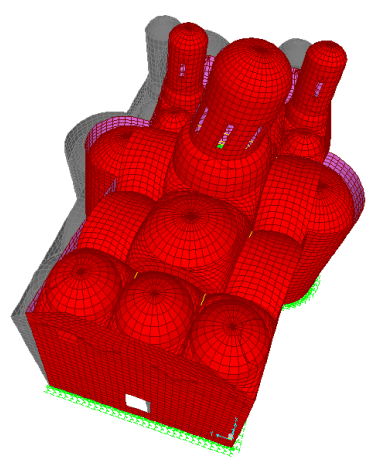

(b) Deformable foundation

Figure 6: $\quad$ (a) $1^{\text {st }}$ Translational eigen-mode $\mathrm{y}-\mathrm{y}, \mathrm{T}_{\mathrm{y}}=0.154 \mathrm{sec}$ modal mass ratio $U_{y}=44.67 \%$. (b) $1^{\text {st }}$ Translational eigen-mode $y-y$, $\mathrm{T}_{\mathrm{y}}=0.197 \mathrm{sec}$ modal mass ratio $\mathrm{U}_{\mathrm{y}}=60.26 \%$.

The modal analysis results, depicted in figures 6(a) and 6(b), demonstrate the first effect of the deformable foundation which is the lengthening of the eigenperiods of the most significant translational modes as well as the mobilization of larger modal mass ratios for these eigen-modes when the foundation was considered as deformable as compared to the corresponding values of the nondeformable foundation. 


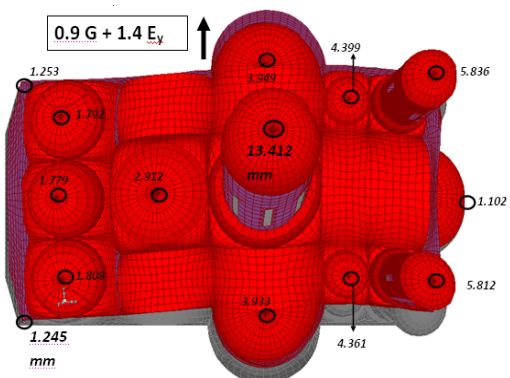

(a)

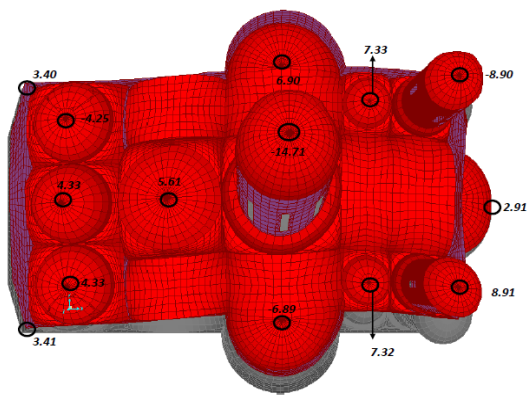

(b)

Figure 7: $\quad$ (a) $0.9 \mathrm{G}+1.4 \mathrm{E}_{\mathrm{y} .}$ Non-Deformable Foundation Max. Disp. Top central dome 13.442mm; (b) 0.9G+1.4E . Deformable Foundation Max. Disp. Top central dome 14.640mm.

Next, the deformations of the structural system were obtained for both the non-deformable and the deformable foundation model. These were obtained for two sets of load combination: the first is designated as $0.9 \mathrm{G}+1.4 \mathrm{Ex}$ and signifies the combination of the gravitational forces $(\mathrm{G})$ with the seismic actions in the East-West $(\mathrm{x}-\mathrm{x})$ longitudinal direction. The seismic action was enforced by applying the dynamic spectral method with a design spectrum specified by the current Greek Seismic Code and for seismic Zone I and soil category A [4]. The second load combination is designated as $0.9 \mathrm{G}+1.4 \mathrm{Ey}$ and signifies the combination of the gravitational forces (G) with the seismic actions in the NorthSouth (y-y) transverse direction (figures 7(a) and 7(b)). Due to the foundation deformability the seismic actions combined with the gravitational forces result in an increase of the horizontal displacement response. This is more pronounced at the top of the peripheral wall where the vaults of the superstructure and roof are supported than at the top of the central dome level. At that level, the maximum displacement is equal to $14.710 \mathrm{~m}$ for the deformable foundation and $13.779 \mathrm{~mm}$ for the non-deformable foundation for the load combination 0.9G+1.4Ex. For the load combination 0.9G+1.4Ey the maximum displacement at the top of the central dome level is $13.442 \mathrm{~mm}$ for the non-deformable foundation as compared with $14.640 \mathrm{~mm}$ for the deformable foundation. Such influence of the foundation deformability is observed in the maximum stress values that develop at either the peripheral walls, the internal transverse wall or the vaults of the superstructure.

Figures 8(a) and 8(b) depict the tensile stress concentration at the outer (top) face of the vaulting system, as it results from load combination 0.9G+1.4Ex. As can be seen, the foundation deformability increases the tensile stress demand at critical locations for the vaulting of the superstructure. Moreover the shear stress $\left(\tau_{12}\right)$ concentration at the internal transverse wall for the load combination $0.9 \mathrm{G}+1.4 \mathrm{E}_{\mathrm{y}}$, shows a considerable increase for the deformable foundation. From the obtained numerical results it can be concluded that the foundation deformability increases the shear stress demand at critical locations where the masonry piers are formed between the door and window openings. These observations, based on the numerical results, are correlated with in-situ evidence 


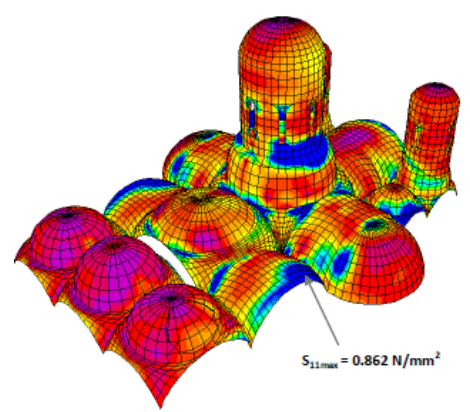

(a)

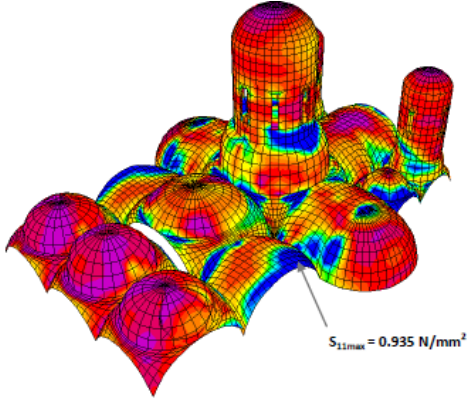

(b)

Figure 8: (a) $0.9 \mathrm{G}+1.4 \mathrm{E}_{\mathrm{x}}$ Non-Deformable Foundation top face Max. Tensile $\boldsymbol{\sigma}_{11}$ 0.862Mpa; (b) $0.9 \mathrm{G}+1.4 \mathrm{E}_{\mathrm{x}}$ Deformable Foundation top face Max. Tensile $\boldsymbol{\sigma}_{11} 0.935 \mathrm{Mpa}$.
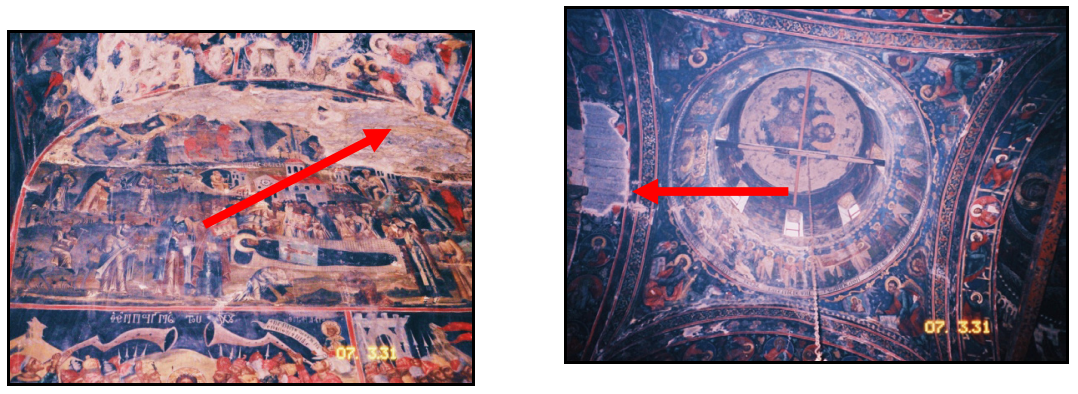

Figure 9: Damage of the internal transverse wall and the adjacent arch.

of damage to the masonry of the vaulting system and the internal transverse wall, as shown (figures 9).

Table 1 lists the assumed mechanical characteristics for the stone masonry [5]. Moreover, a Mohr-Coulomb failure envelope was adopted for the in-plane shear limit state of the stone masonry, when a $\boldsymbol{\sigma}_{\mathbf{n}}$ normal stress is acting simultaneously, that is defined through the relationship (1) $[1,2,6]$.

$$
\mathrm{f}_{\mathrm{vk}}=\mathrm{f}_{\mathrm{vko}}+0.4 \boldsymbol{\sigma}_{\mathrm{n}}
$$

where $f_{v k o}$ is the shear strength of the stone masonry when the normal stress is zero; $f_{v k o}$ was assumed to be equal to $0.192 \mathrm{~N} / \mathrm{mm}^{2}$. Table 1 lists the assumed mechanical characteristics for the stone masonry in terms of Young's modulus and Poisson's ratio as well as compressive and tensile strength values.

Next, certain commonly used masonry failure criteria were adopted for either in-plane tension/compression or shear/compression or out-of-plane tension. All the masonry parts of the studied structures were examined in terms of in-plane and out-of-plane stress demands posed by the considered load combinations against the corresponding capacities, as these capacities were obtained by applying the Mohr-Coulomb criterion of equation (1) or the stone masonry compressive and tensile strength limits listed in Table 1. With $\mathbf{R} \boldsymbol{\sigma}$ or with $\mathbf{R} \boldsymbol{\tau}$ the 
Table 1: $\quad$ Assumed mechanical characteristics of the stone masonry.

\begin{tabular}{|l|c|c|c|c|c|}
\hline & $\begin{array}{c}\text { Young's } \\
\text { Modulus } \\
\left(\mathrm{N} / \mathrm{mm}^{2}\right)\end{array}$ & $\begin{array}{c}\text { Poisson's } \\
\text { Ratio }\end{array}$ & $\begin{array}{c}\text { Compressive } \\
\text { Strength } \\
\left(\mathrm{N} / \mathrm{mm}^{2}\right)\end{array}$ & $\begin{array}{c}\text { Tensile Strength } \\
\text { normal /parallel } \\
\text { bed-joint }\left(\mathrm{N} / \mathrm{mm}^{2}\right)\end{array}$ & $\begin{array}{c}\text { Shear } \\
\text { strength } \\
\mathrm{f}_{\mathrm{vko}} \\
\left(\mathrm{N} / \mathrm{mm}^{2}\right)\end{array}$ \\
\hline $\begin{array}{l}\text { Limit } \\
\text { values }\end{array}$ & 2500 & 0.2 & 3.818 & $0.250 / 0.800$ & 0.192 \\
\hline
\end{tabular}

Ratio $\mathbf{R}_{\boldsymbol{\tau}}$ values of in-plane shear strength / shear demand

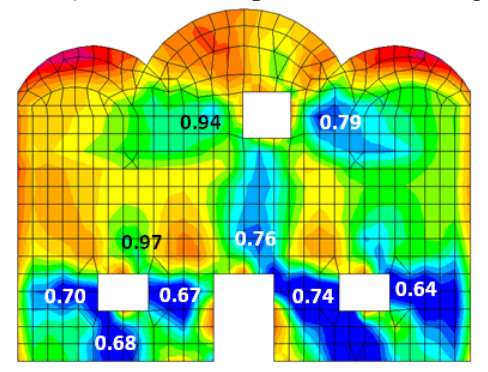

(a)

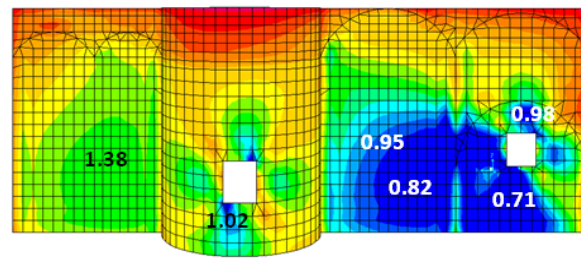

(c)

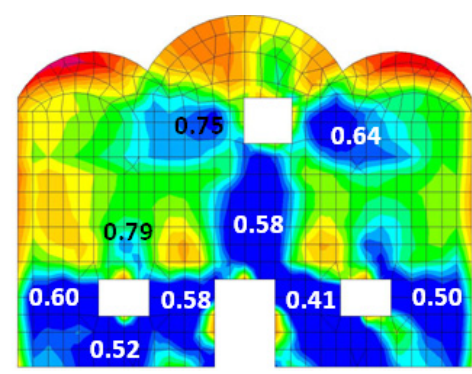

(b)

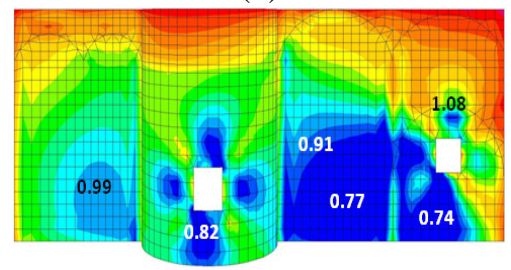

(d)

Figure 10: (a) Non-Deformable Foundation Internal Transverse Wall, 0.9G+1.4Ey; (b) Deformable Foundation Internal Transverse Wall, 0.9G+1.4Ey; (c) Non-Deformable Foundation North Peripheral Longitudinal Wall, 0.9G+1.4Ex; (d) Deformable Foundation North Peripheral Longitudinal Wall, 0.9G+1.4Ex.

ratio of the in-plane tensile or shear strength value over the corresponding demand is signified, whereas with $\mathbf{R}_{\mathbf{M}}$ the ratio of the out-of-plane tensile strength value over the corresponding demand is denoted. Ratio values smaller than one ( $\left.\mathbf{R} \boldsymbol{\sigma}, \mathbf{R} \boldsymbol{\tau}, \mathbf{R}_{\mathbf{M}}<1\right)$ predict a corresponding limit state condition. As can be seen, the followed methodology is based on combining numerical stress demands resulting from elastic analyses with limit-state strength values. A different approach is to incorporate these limit-state strength values in a nonlinear push-over type of analysis (see Manos et al. [1]). It was shown that the methodology applied here correlates quite well with the non-linear approach in predicting regions of structural damage. Figures 10(a) and 10(b) depict the R ratio values of the in-plane shear strength / shear demand for the load combination $0.9 \mathrm{G}+1.4 \mathrm{Ey}$ for the internal transverse wall, which separates the main church from the women's quarters situated at the west portion of the 
church. This wall as well as the internal facades of all the peripheral walls, vaults and domes are decorated with very valuable frescos that bear signs of extensive damage (see figure 9). Figures 10(c) and 10(d) depict values of ratio R $\boldsymbol{\tau}$ for the North peripheral wall $(0.9 \mathrm{G}+1.4 \mathrm{Ex})$. Damage is predicted by these numerical analysis results as can be seen from the $\mathbf{R} \boldsymbol{\tau}$ ratio values that are well below one $(\mathbf{R} \boldsymbol{\tau}<1)$ in many locations. Moreover, the deformability of the foundation leads this ratio to obtain even smaller values than for the case of the non-deformable foundation, which demonstrates the detrimental effect of the flexibility of the foundation also for this church.

\section{The Profitis Ilias at Siatista-Kozani}

This is also a Post-Byzantine three nave Basilica built in 1701 AD on the top of a hill in the town of Siatista of the prefecture of Kozani. It also has a wooden roof without the vaulting system of the Basilica church described in section 2 . The horizontal dimensions of this church are $23.25 \mathrm{~m}$ in length and $16.60 \mathrm{~m}$ in width. The top of the roof lies at $7.1 \mathrm{~m}$ from the floor level of the interior of this church. The naves are formed by 4-column colonnades (figures 11(a)) built with stone masonry. The lower part of the key of each arch of these colonnades lies at $5.25 \mathrm{~m}$ from the floor level of the interior of this church. All the exterior walls are made of stone masonry. Apart from the main church a narthex was built at the North side at a later stage; this is of a relatively lower height than the main church.

The West part of the church is allocated to the women's quarters that are separated from the rest of the interior by a mid-transverse wall. The South longitudinal wall is supported by a system of wooden beams as is shown in figure 11(b). These were installed after the Kozani-1995 earthquake sequence. Additional wooden supports are also placed at the mid-transverse wall as well as at the mid-span of a longitudinal beam that spans the women quarters from East to West. According to past records, the structural system of this church showed signs of distress from soil-settlement sometime before the occurrence of this particular earthquake sequence. The records do not give information of any

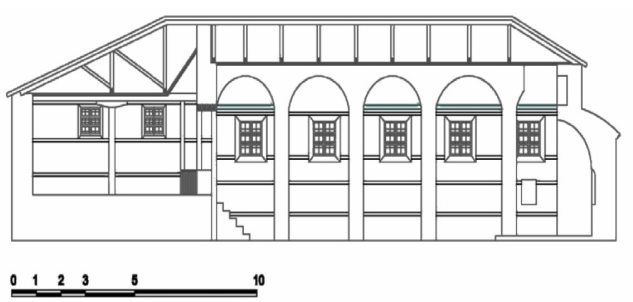

(a)

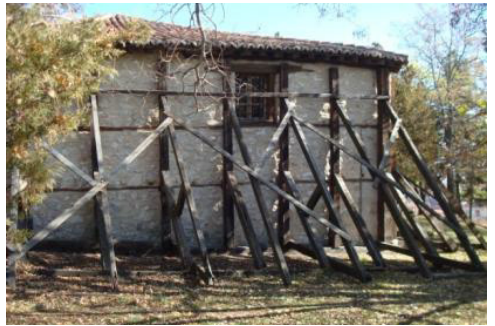

(b)

Figure 11: The church of Profitis Ilias at Siatista-Kozani. (a) Longitudinal cross-section; (b) Wooden shoring of South longitudinal wall. 
countermeasures being taken in the past up to the point of the earthquake occurrence. The main structural damage, as recorded after this earthquake sequence, is described below. Inclination of the South longitudinal wall outwards that is accompanied with extensive cracking at its joints with the East and West exterior masonry walls as well as with the mid-transverse wall. Cracking is evident at the arches of the colonnades. Despite the fact that 18 years have passed since this earthquake damage, the counter measures so far are in the form of the temporary wooden shoring as well as the renovation of the wooden roof.

\subsection{Numerical simulation of the influence of the soil deformability}

The current numerical investigation of this church included the following:

- Simulation of the behaviour assuming non-deformable supports at the foundation level.

- Simulation of the behaviour assuming deformable supports at the foundation level, introducing at this level elastic springs with properties reflecting the actual soil deformability that was found from in-situ sampling. The soil consists of clay in its upper layers. For quantifying the stiffness of these soil layers use was made of the data from three bore-holes drilled in the vicinity of the church relevant to the constitution of the soil deposits at a depth up to $15 \mathrm{~m}$. All the numerical simulations assumed elastic behaviour with relatively low-values of the modulus of elasticity for the stone masonry equal to $E=1660 \mathrm{MPa}$. The system of the wooden roof was modeled as well as all the wooden elements that connect the longitudinal and transverse walls with the interior colonnades and the midtransverse wall. A small number of mortar samples were taken from the church. The natural stone used in the masonry elements is a type of slate with a compressive strength equal to $24 \mathrm{MPa}$, as given in the literature survey.

Table 2: $\quad$ Assumed mechanical characteristics of the stone masonry.

\begin{tabular}{|l|c|c|c|c|c|}
\hline & $\begin{array}{c}\text { Young's } \\
\text { Modulus } \\
\left(\mathrm{N} / \mathrm{mm}^{2}\right)\end{array}$ & $\begin{array}{c}\text { Poisson's } \\
\text { Ratio }\end{array}$ & $\begin{array}{c}\text { Compressive } \\
\text { Strength } \\
\left(\mathrm{N} / \mathrm{mm}^{2}\right)\end{array}$ & $\begin{array}{c}\text { Tensile Strength } \\
\text { normal / parallel } \\
\text { bed-joint }\left(\mathrm{N} / \mathrm{mm}^{2}\right)\end{array}$ & $\begin{array}{c}\text { shear } \\
\text { strength } \\
\mathrm{f}_{\mathrm{vko}}\left(\mathrm{N} / \mathrm{mm}^{2}\right)\end{array}$ \\
\hline $\begin{array}{l}\text { Limit } \\
\text { values }\end{array}$ & 1660 & 0.2 & 1.0 & $0.10 / 0.25$ & 0.10 \\
\hline
\end{tabular}

Table 2 lists the assumed mechanical characteristics for the stone masonry in terms of Young's modulus and Poisson's ratio as well as compressive and tensile strength values. These values were based mainly from data included in the literature. From the comparison of the limit strength values of Table 2 with those of Table 1 it can be easily seen that the stone masonry of the church of Profitis Ilias of Siatista is much weaker than that of the church of Agia Triada at Vithos. The same Mohr-Coulomb failure envelope described by equation (1) was also adopted here for the in-plane shear limit state of this stone masonry. As was done before, the values of the strength over demand ratios at the most critical locations of the masonry walls and vaults were obtained by comparing the 
strength values listed in table 2 with the corresponding demand values as they were obtained from the numerical simulation. The ratio of the in-plane tensile or shear strength value over the corresponding demand is signified by $\mathbf{R}_{\boldsymbol{\sigma}}$ or $\mathbf{R}_{\tau}$ whereas $\mathbf{R}_{\mathbf{M}}$ denotes the ratio of the out-of-plane tensile strength value over the corresponding demand. Ratio values smaller than one ( $\mathbf{R} \boldsymbol{\sigma}, \mathbf{R} \boldsymbol{\tau}, \mathbf{R}_{\mathbf{M}}<1$ ) predict a corresponding limit state condition

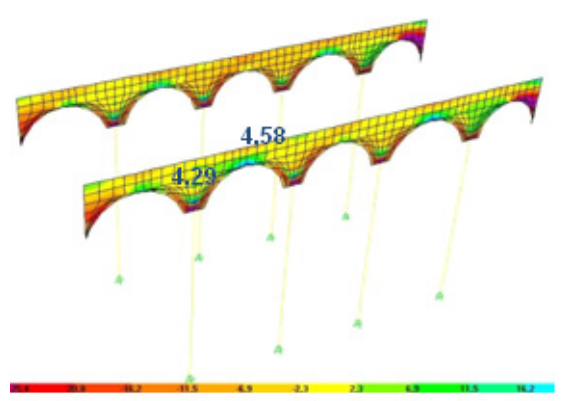

(a)

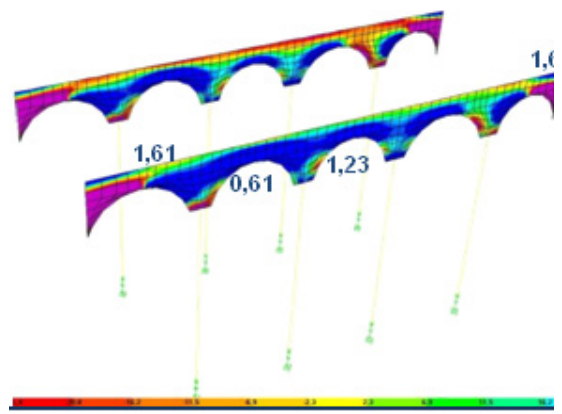

(b)

Figure 12: (a) G+0.3Q. Non-Deformable soil $\mathbf{R}_{\boldsymbol{\sigma}}$ Ratio of in-plane strength / demand F11 parallel to bed joint. (b) G+0.3Q. Deformable soil $\mathbf{R}_{\boldsymbol{\sigma}}$ Ratio of in-plane strength / demand F11 parallel to bed joint.

Figures 12(a) and 12(b) depict $\mathbf{R}_{\boldsymbol{\sigma}}$ ratio values for the masonry arches above the internal colonnades. These $\mathbf{R}_{\boldsymbol{\sigma}}$ ratio values of in-plane strength / demand were found by applying the limit tensile strength scenario parallel to bed-joint (F11). The demands in these figures were obtained for the load combination $\mathrm{G}+0.3 \mathrm{Q}$. As can be seen from the above figures, the $\mathbf{R}_{\mathbf{\sigma}}$ ratio values are smaller for the deformable than the non-deformable foundation, which demonstrates the detrimental effect of the foundation deformability for this church even only for the gravitational forces. For the load combination 1.3G+1.5Q, that dictates the design for the gravitational forces under current code provisions, the above ratio values will become even smaller, which signifies that the colonnades cannot withstand the maximum gravitational forces. This is verified by the observed damage which is quite evident for these structural elements in this church as it stands today being supported after the earthquake event of 1995 by temporary wooden shoring internally as well as externally.

From the evaluation of the demands obtained from this numerical simulation as compared with the limit strength values adopted for the stone masonry of this church it can be concluded that the deformability of the foundation results in strength / demand ratio values smaller than the corresponding ratio values for the non-deformable foundation. This signifies critical regions of the masonry structural elements that cannot withstand the forces, as prescribed by the current code provisions.

Moreover, such an evaluation can also explain, up to a point, the development of the existing current state of structural damage. Gaining such confidence in the employed methodology the designer gains also the advantage in evaluating with 
the same methodology the effectiveness of a potential retrofitting scheme. In order for such retrofitting scheme to be effective the resulting strength / demand ratios should attain values larger than the corresponding values without this retrofitting scheme and, if possible, larger than 1 . Such an evaluation has been performed for the most vulnerable structural elements of this church; that is the internal colonnades, the South peripheral wall and the East peripheral wall with the apses. The existing or potential damage is predicted by the numerical analysis results when the strength / demand ratio values are well below 1 . This is shown in figure 13 for the internal colonnade. In almost all structural elements the out-of-plane tensile behaviour results in strength / demand ratios with values well below one $\left(\mathbf{R}_{\mathbf{M}}<1\right)$. The internal colonnade has visible signs of out-of-plane displacements and extensive cracking that are in agreement to the distress predicted by the followed methodology.

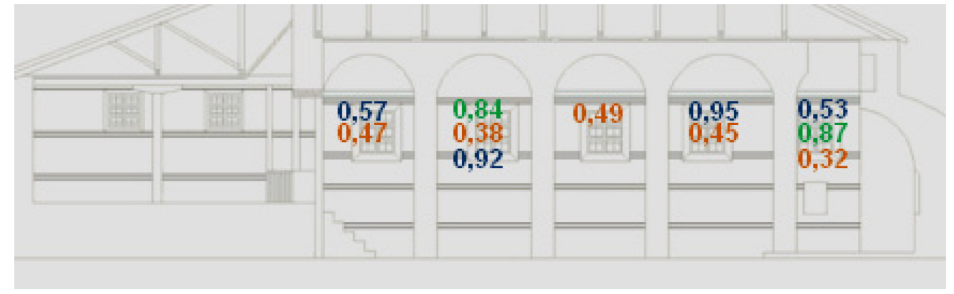

Figure 13: Internal colonnade. Regions with small values of the strength / demand $\mathbf{R}_{\mathbf{M}}$ out-of-plane tensile behaviour (orange color), $\mathbf{R}_{\tau}$ inplane shear behaviour (green color), $\mathbf{R}_{\boldsymbol{\sigma}}$ in-plane tensile behaviour (blue color).

\section{Conclusions}

1. The eigen-periods, eigen-modes, and the deformation patterns to horizontal earthquake actions of the examined churches predicted numerically predicts large out-of-plane displacements at the top of their longitudinal peripheral walls. The presence of stone masonry vaulting system increases the stiffening effect at the top of the peripheral wall level; however, such vaulting system also adds considerable masses at a high level that generate large seismic actions.

2. The predicted regions most vulnerable to damage are near the door and window openings for the in-plane behaviour; this agrees reasonably well qualitatively with observed damage, although the numerical simulation is based on elastic behaviour. For a superstructure consisting of vaults and domes, large seismic forces are generated leading to stress concentration at the bases of the domes and vaults and at the keys of the arches. Further investigation is needed to establish appropriate limit-state criteria for these stone masonry elements.

3 . The foundation deformability was investigated introducing linear deformable springs at the foundation level. The results of such a numerical approximation combined with the followed methodology of limit state criteria of strength/ 
demands ratio values ( $\mathbf{R} \boldsymbol{\tau}, \mathbf{R} \boldsymbol{\sigma}, \mathbf{R}_{\mathbf{M}}$ ) demonstrates in all the examined cases that the foundation deformability, when combined with the gravitational forces and seismic actions, leads to $\mathbf{R} \boldsymbol{\tau}, \mathbf{R} \boldsymbol{\sigma}$, and $\mathbf{R}_{\mathbf{M}}$ ratio values that are considerably smaller than for the case of non-deformable foundation thus verifying the detrimental effect of the foundation deformability in all the examined cases.

\section{References}

[1] Manos G.C., Soulis V., Diagouma A. (2008) "Numerical Investigation of the behaviour of the church of Agia Triada, Drakotrypa, Greece”, Journal in Advances in Engineering Software 39, 284-300.

[2] Manos George, Soulis V., Felekidou O., Matsou V. (2010) “A Numerical Investigation of the Dynamic and Earthquake Behaviour of Byzantine and Post-Byzantine Basilicas”, 9th U.S. and 10th Canadian Earthq. Eng. Conf., Canada.

[3] Manos G. C., (2011) "Consequences on the urban environment in Greece related to the recent intense earthquake activity", Int. Journal of Civil Engineering and Architecture, Volume 5, No. 12 (Serial No. 49), pp. 10651090.

[4] Provisions of Greek Seismic Code (2003), Organization of Earthquake Planning and Protection of Greece OASP, Dec. 1999 published by OASP. Revisions of seismic zonation introduced in 2003, Government Gazette, $\Delta 17 \alpha / 115 / 9 / \Phi N 275$, No. 1154, Athens, 12 Aug. 2003.

[5] European Committee for Standardization, Euro-code 6 (2005); "Design of Masonry Structures, Part 1-1:General Rules for Building. Rules for Reinforced and Un-reinforced Masonry”, EN 1996-1-1:2005.

[6] Earthquake Engineering Retrofitting of Heritage Structures (2013) "Design and evaluation of strengthening techniques”, Edited by: S. Syngellakis, Wessex Inst. of Technology, UK, ISBN: 978-1-84564-754-4, eISBN: 978-184564-755-1.

[7] V. Dimitriadis “An ordinance for the erection of the first church in Gianitsa”, Mekedonika, Vol. 9, Society for Mecedonian Studies, Thessaloniki 1969. 